\title{
Epidemiological Study on Ticks in Farm Animals in Selected Areas of Sri Lanka
}

\author{
D. R. Liyanaarachchi, H.R.N. Jinadasa, P.R.M.P. Dilrukshi ${ }^{1}$ and R.P.V.J. Rajapakse* \\ Faculty of Veterinary Medicine and Animal Science \\ University of Peradeniya \\ Sri Lanka
}

\begin{abstract}
Ticks are the most important ecto-parasites of livestock in tropical and subtropical areas, and are responsible for severe economic losses in livestock. Ticks are a major veterinary concern as they transmit pathogens, produce tick paralysis or toxicosis, and reduce production in livestock. The cost of worldwide economic losses and the additional burden of protecting livestock against ticks and tick-borne diseases are now estimated to be billions of dollars annually.The main objective of this study was to determine the tick diversity in farm animals from selected areas of Sri Lanka. Additionally, the possibility of the introduction of tick species from wildlife into livestock was also investigated. Ticks were collected from livestock in 30 locations in the Wet zone and 30 locations in the Dry zone (representing both rural and urban regions), covering most parts of Sri Lanka, during the years 2009 and 2010. Eighteen (18) tick species were recorded in the present study, indicating a fair increase in tick species reported in livestock in Sri Lanka. The findings included rare tick species, which has been previously reported only on wild animals. Some tick species showed a host preference while others have expanded their geographical and host range.
\end{abstract}

Keywords: Tick-borne diseases, economic loss, new tick populations

\section{INTRODUCTION}

Ticks belong to the phylum Arthropoda and make up the largest collection of species in the order Acarina. Ticks are divided into two groups; soft bodied ticks (argasidae) and hard bodied species (ixodidae) (Sonenshine, 1991). Ticks are the most important ecto-parasites of livestock in tropical and sub-tropical areas and cause great economic losses in several ways including thetransmission of diseases, causing paralysis or toxicosis and physical damage to livestock (Klompen et al., 1996; Snelson, 1975). However, the major losses attributable to ticks are due to their ability to transmit protozoan, rickettsial and viral diseases of livestock (Frans, 2000). For example, tickborne protozoan diseases (e.g. theileriosis and babesiosis) and rickettsial diseases (e.g.anaplasmosis and cowdriosis) and tick-associated dermatophilos is are major health and management issues of livestock in many developing countries.

National Science foundation, 47/5,Maitland Place, Colombo 7, Sri Lanka

Corresponding author :jayanthar@pdn.ac.lk 
The economically most important ixodid ticks of livestock in tropical regions belong to the genera Hyalomma, Rhipicephalus and Amblyomma (Frans, 2000). Genus Rhipicephalus include approximately 75 species worldwide, including those belonging to Boophilus group which has been recently merged to this genus (Geevarghese and Mishra, 2011). In fact, former Boophilus spp. in Sri Lanka is now named as Rhipicephalus boophilus (Dilrukshi, 2002).

One of the most important tick-borne diseases in Asian countries is bovine babesiosis and the vectors are $R$. boophilus, Haemaphysalis spp. (especially $H$. bispinosa), Hyalomma marginatum, Rhipicephalus spp., Ixodes spp. and Dermacentor spp. (Sonenshine, 1993). Similarly, $T$.annulata is a parasite that causes tick-borne theileriosis, also known as tropical theileriosis that infects cattle and other livestock (Conrad et al., 1985). Other animal species including buffalo, cat and deer are also susceptible to theilerial infections in various parts of the world. Possible vectors for theileriosis in these animals are Rhipicephalus spp., Amblyomma spp. and Dermacentor spp. (Kocan and Kocan, 1991). Rikettsial disease heartwater is transmitted by Amblyomma spp. while anaplasmosis is transmitted by Demacentor spp. and Rhipicephalus spp. (Sonenshine,1993). Additionally, several other Amblyomma species were naturally infected with Rickettsia species of unknown pathogenicity (Labruna et al., 2004 Lemos et al., 1997 ) and also with unidentified species of Borrelia and Ehrlichia (Gehrke et al., 2002).

Common tick-borne diseases reported in livestock and humans in Sri Lanka are babesiosis, theileriosis, anaplasmosis, spirochaetosis, piroplasmosis, hepatazoonosis, Nairobi sheep disease, Q fever, rickettsial infections including spotted fever, ehrlichiosis, and tick thyphus (Seneviratna, 1966). Bovine babesiosis in Sri Lankais caused by Babisia bigemina, B. argentina and B. bovis and the principle vector is $R$. boophilus (Weilgama, 2005). Additionally, $R$. boophilus are probably the most important vectors for several parasites of cattle in Sri Lanka including Theileria mutans, Anaplasma marginale, A. centrale, Coxiella burneti and Ehrlichia bovis (Seneviratna, 1965).

The first record of a disease transmitted by ticks in Sri Lanka was in 1917 when Sturgess encountered cases of piroplasmosis (babesiosis) in cattle due to B. bigemina in Western Province and Central Province (Sturgess, 1917). In 1935 Craw ford and co-workers identified Anaplasma marginale and Theileria mutants from cattle (Crawford, 1935). Theileria annulata was identified in 1960 in cattle (Seneviratna and Kumaraswamy, 1960) and B. bovis was reported from cattle (Bos taurus) in a hill country farm in 1961 at autopsy (Bandaranayake, 1961). Presence of Ehrlichia bovis in cattle (Seneviratna and Dhanapala, 1963) and Gonderia ovis on goats were reported from Central Provincein 1963 (Seneviratna and Subasinghe, 1963). In Sri Lanka bovine spirochaetos is is caused by Borrelia theileri which is transmitted by $R$. boophilus (Seneviratna, 1965). More recently, Nairobi sheep disease (NSD) virus was isolated from $H$. intermedia ticks from goats (Perera et al., 1996). Further, H. bispinosa ticks transmitted Theileria spp. from one calf to another under experimental conditions while $H$. marginatum isaaci and $R$. haemaphysaloides failed to transmit the disease (Weilgama, 1985).

It is well established that ticks and tick-transmitted infections have coevolved with various wild animal hosts which often live in a state of equilibrium with ticks. Wild animals provide a reservoir for ticks and tick-borne pathogens of livestock, pets and humans (Jongejan and Uilenberg, 2004). These tick species and diseases transmitted by them have only affected livestock when the wild hosts come into contact with livestock, for example due to livestock movement into endemic regions (Jongejan and Uilenberg, 2004). On the other hand, 
movement of infested livestock into disease free areas may introduce new tick species into wildlife and effectively create new niches for particular tick species (and diseases transmitted by them). Unlike livestock, under certain circumstances it is nearly impossible to eradicate diseases from wildlife reservoirs. Therefore, the interaction between livestock and wildlife is a major determinant of the efficacy of control programs for tick infestations and tick-borne diseases. This is particularly important for a developing country like Sri Lanka where livestock farmers experience regular conflicts with wildlife at an increasing rate due to fragmentation of land resources. In addition, particularly in the dry zone of Sri Lanka, it is a common practice by the livestock farmers to let the large extensively managed herds of cattle and goats to forage in the forest areas including protected areas such as national parks, aggravating the problem further the in addition to creating new infection niches, can be detrimental to the wildlife health as well.

\section{Tick diversity studies in Sri Lanka}

Despite the importance of ticks as vectors for several major diseases of animals and humans, studies on the taxonomy and ecology of ticks in Sri Lanka are scanty. The most comprehensive study on hard ticks in Sri Lanka have been conducted by Seneviratna in 1965. This study reported 26 species of ticks belonging to nine genera from island wide samples on wild and domestic animals. Halim and co-workers recorded tick species on goats in the dry zone of the country (Halim et al., 1983). Later citations are short reports or works focused on tick-borne diseases carrying brief mentioning tick species. The latest comprehensive eco-taxonomic study on cattle ticks in Sri Lanka was conducted by Dilrukshi (2002), where eight tick species were reported. Hence according to literature, 27 species of ixodid ticks belonging to seven genera (according to recent classification) have been reported in Sri Lanka (Seneviratna, 1965; Halim et al., 1983; Weilgama 1999; Dilrukshi, 2002). Out of these 27 species, 14 species had been recorded in farm animals (Table 1).

Information on island wide distribution of ticks on livestock is very limited in Sri Lanka. Additionally, studies on the transmitting wildlife-restricted tick species to livestock due to the interactions of wild animals with domestic stocks are also lacking in Sri Lanka. Therefore, the main objective of this study was to determine the tick diversity on farm animals and their significance to disease transmission in Sri Lanka. Additionally, the possibility of introducing tick species from wildlife into livestock was also investigated. 
Table 1. Previously recorded tick species of livestock in Sri Lanka

\begin{tabular}{|c|c|c|}
\hline Host & Tick species & Source \\
\hline Cattle & $\begin{array}{l}R . \text { boophilus, } R . \text { sanguineus, } R . \text { haemaphysaloides, } \\
H . \quad \text { bispinosa, } H . \quad \text { intermedia, } H . \quad \text { spinigera, } \\
\text { A. integrum, H. marginatum isaaci, } H . \text { brevipunctata }\end{array}$ & $\begin{array}{l}\text { Seneviratna, } 1965 \\
\text { Dilrukshi, } 2002\end{array}$ \\
\hline Cat & H. bispinosa, $H$. intermedia, $R$. sanguineus & Seneviratna, 196 \\
\hline Buffalo & $\begin{array}{l}R . \text { boophilus, } R . \text { sanguineus. } H . \text { bispinosa, } H . \\
\text { intermedia, } R . \text { haemaphysaloides, A. integrum, } A . \\
\text { testudinarium, H. marginatum isaaci, N. monstrosum, } \\
\text { H. brevipunctata, A. clypeolatum }\end{array}$ & $\begin{array}{l}\text { Seneviratna, } 1965 \\
\text { Weilgama, } 1999\end{array}$ \\
\hline Goat & $\begin{array}{l}R . \text { boophilus, } R \text {. sanguineus, } R \text {. haemaphysaloides, } H . \\
\text { bispinosa, H. intermedia,H.cuspidata, H. marginatum } \\
\text { isaaci, H. leachi var indica, }\end{array}$ & Seneviratna, 1965 \\
\hline Sheep & $\begin{array}{l}R . \text { boophilus, } R . \text { sanguineus, } R \text {. haemaphysaloides, } H . \\
\text { bispinosa,H. intermedia, H. marginatum isaaci, }\end{array}$ & Seneviratna, 1965 \\
\hline Rabbit & $R$. sanguineus & Seneviratna, 1965 \\
\hline
\end{tabular}

\section{METHODOLOGY}

Ticks were collected from farms in 30 locations in the wet zone and the same number of locations in the dry zone, covering most parts of the island during years 2009 and 2010 (Fig. 1). Both rural and urban regions were included in the study. Among these locations, most of the sampling points were distributed in the Kandy district representing wet zone, and Anuradapura district representing dry zone. The total numbers of ticks collected were 16,278 from 1498 hosts. The ticks were collected directly from animal body during field visits, and through veterinary clinics. Farm animals comprised cattle, buffalo, goat, domestic fowl, pig, rabbit and sheep. Collected ticks were initially stored in $70 \%$ ethanol and later examined under the dissecting microscope for species identification by using keys described earlier (Nuttall and Warburton., 1915; Trapido et al., 1963; Sharif, 1928; Kaiser and Hoogstraal, 1964; Seneviratna, 1965). 


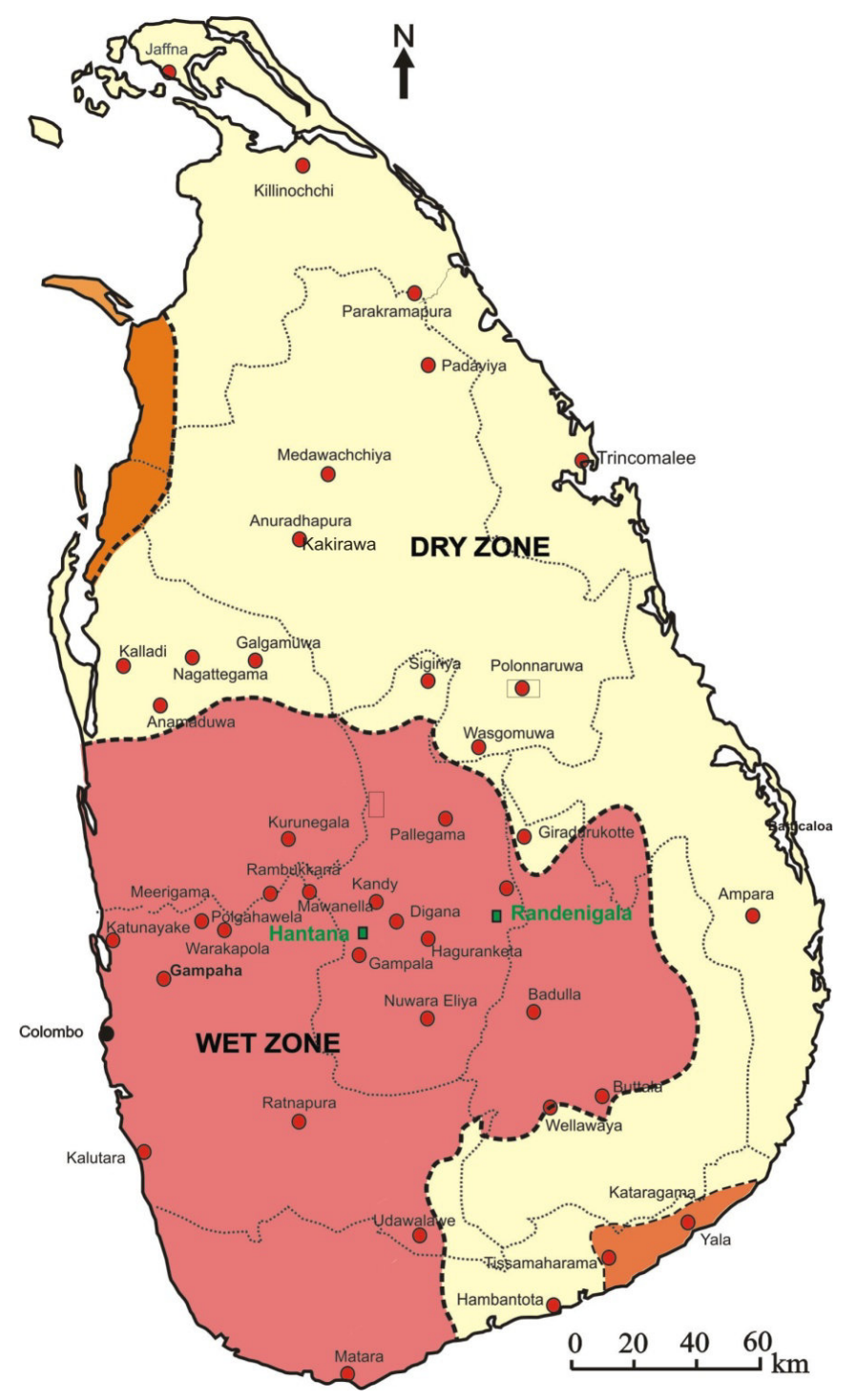

Fig. 1. Study sites in wet and dry zone

\section{RESULTS}

Eighteen species were recorded from 1498 farm animals representing several regions of Sri Lanka. Compared to the previous studies, the number of tick species parasitizing farm animals had increased by $28 \%$ (Table I and 2). However, Haemaphysalis leachi var indica previously reported from goat in a single farm in North Central province (and in wildlife) was not reported from any host in the current study (Table 1 and 2).Similarly, H. minuta previously reported only from domestic fowl was also not reported from any host in this study (Table 1 and 2). 
Table 2. Distribution of tick species among livestock hosts.

\begin{tabular}{|c|c|c|c|c|c|c|c|c|}
\hline $\begin{array}{l}\text { Host }(\mathbf{n}) \rightarrow \\
\text { Tick species } \downarrow\end{array}$ & 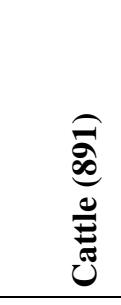 & 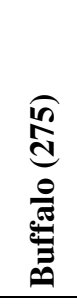 & 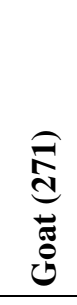 & 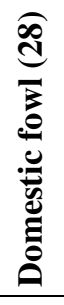 & $\underset{\substack{\infty \\
\stackrel{\infty}{\infty}}}{\stackrel{\infty}{2}}$ & 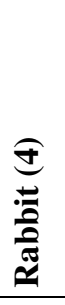 & 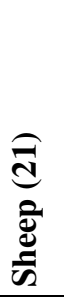 & 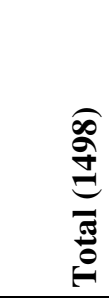 \\
\hline R. boophilus & 10,823 & 40 & 19 & & & & & 10,882 \\
\hline$R$. sanguineus & 2175 & 156 & 152 & & 16 & 41 & 44 & 2584 \\
\hline R. haemaphysaloides & 602 & 57 & 31 & & 4 & 15 & 5 & 714 \\
\hline H.bispinosa & 367 & 3 & 258 & & & & 3 & 631 \\
\hline H. intermedia & 251 & 22 & 383 & 24 & 10 & 5 & 29 & 724 \\
\hline H. marginatumisaaci & 142 & 302 & & & & & & 444 \\
\hline H. cuspidata & 15 & 2 & 9 & & & & 5 & 31 \\
\hline A. testudinarium & 50 & 35 & 8 & 11 & & & & 104 \\
\hline H. turturis & & 2 & & 3 & & & & 5 \\
\hline H. spinigera & 1 & & & 2 & & & & 3 \\
\hline H. hystricis & 1 & 2 & 2 & & & & & 5 \\
\hline H. kyasanursensis & 2 & & & & & & & 2 \\
\hline H. aculeata & 3 & & & 3 & & & & 6 \\
\hline A. integrum & 57 & 47 & & 3 & & & & 107 \\
\hline A. clypeolatum & 3 & 1 & & & & & & 4 \\
\hline H. brevipunctata & 19 & 4 & & & & & & 23 \\
\hline D. auratus & & & & 3 & & & & 3 \\
\hline N. monstrosum & & 6 & & & & & & 6 \\
\hline
\end{tabular}

New species recorded from livestock in the current study are indicated in bold.These very rare species were previously reported only from wildlife.

Further, despite the previous records, both $R$. boophilus and $H$. marginatum isaaci were not observed in sheep while $H$. marginatum isaaci was not even observed in goat in this study. Similarly, $R$. sanguineus, $R$. haemaphysaloides and $H$. bispinosa was not reported from domestic fowl and A. integrum was not observed in pigs (Table 1 and 2). R. sanguineus, $R$. haemaphysaloides and $H$. intermedia was observed in pigs. Whereas, $R$. haemaphysaloides and $H$. intermedia were reported from rabbit. These ticks were not previously reported from the respective hosts in Sri Lanka. Interestingly, several very rare species which hadbeen previously reported only from wild animals, including Haemaphysalis turturis, H. hystricis, H. kyasanursensis, Dermacentor auratus, and immature H. aculeate were reported from farm animals, suggesting the possibility of livestock acquiring these ticks from the wildlife (Table 2 and Fig.2).Further, Amblyomma testudinarium, A. clypeolatum, and H. cuspidata which had been previously reported only from buffalo and goat respectively from rural areas in 
North Central Province had spread among a wide range of farm animals including several urban and suburban areas of the country (Fig.3).

$R$. boophilus was the most prevalent tick species in livestock followed by $R$. sanguineus. Other tick species with significantly higher prevalence were H.intermedia, $R$. haemaphysaloides, H. bispinosa and H. marginatum isaaci (Table 2). On the other hand, $H$. kyasanursensis had the lowest prevalence and it was the only species reported from cattle. Similarly, H. turturis, H. spinigera, H. hystricis, H. aculeata, A. clypeolatum, D. auratus, and N. monstrosum had very low prevalence (Table 2). Moreover, all of these low prevalent tick species were observed in less than three hosts (Table 2).

Overall our data indicates that the number of tick species infesting livestock of Sri Lanka has increased.Some of them have expanded the geographicalboundaries and host range compared to previous reports. More importantly there is evidence that tick species which were previously confined to wildlife are now infesting the domestic animals.

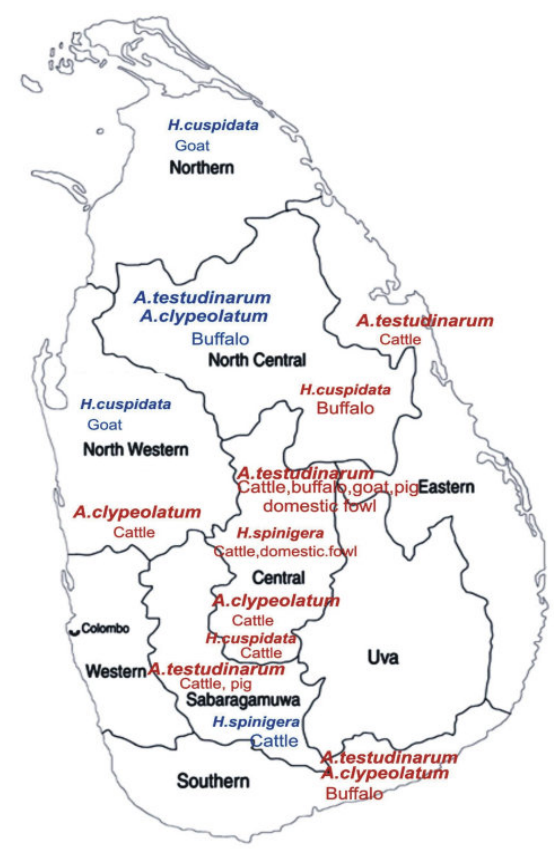

Fig. 2 .

Expansion of geographical distribution and host range in A. testudinarium, A. clypeolatum, and $\boldsymbol{H}$. cuspidata. Previously reported distribution is depicted in blue while current distribution is shown in red.

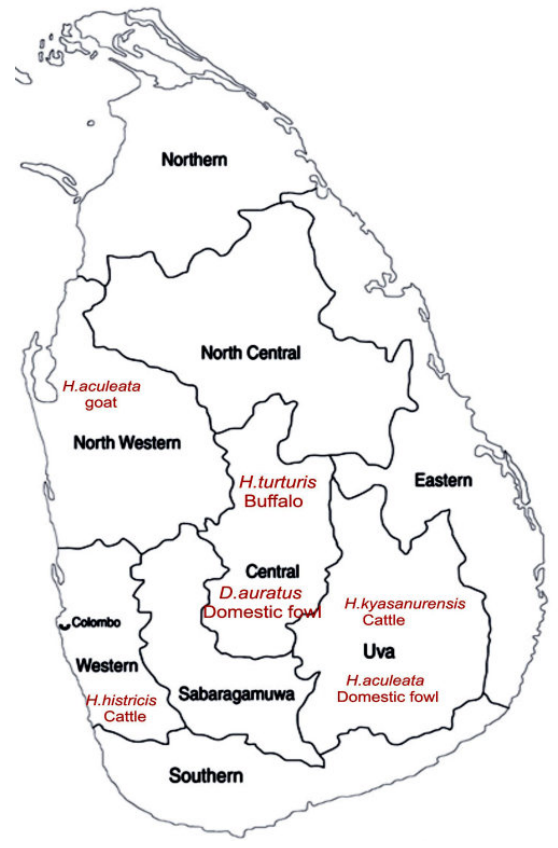

Fig. 3.

Geographical distribution and host range of newly recorded ticks from livestock. 


\section{DISCUSSION AND CONCLUSIONS}

Eighteen tick species recorded from livestock in the current study represent a fair increase compared to the previous report of 14 species. However, few species of previously recorded ticks could not be observed in the present study in their respective hosts. $R$. haemaphysaloides and $H$. intermedia from pigs and rabbit and $R$. sanguineus from pigs were reported for the first time in Sri Lanka suggesting the consideration expansion of host range in these species of ticks. Furthermore, three tick species (A. testudinarium, A. clypeolatum and $H$. cuspidata) previously recorded only on a single host in rural areas of North Central Province hadclearly expanded their geographicalboundaries and host range.Some tick species were highly abundant on a particular host, for example $R$. boophiluson cattle and $H$. marginatum on buffalo in the dry zone. H. intermedia showed high prevalence in goats in the dry zone while $H$. bispinosa was the most prevalent tick species in the wet zone.

In overall, $R$. boophilus was the most prevalent tick species in livestock followed by $R$. sanguineus. Certain tick species (H. intermedia, $R$. haemaphysaloides, $H$. bispinosa and $H$. marginatum isaaci) were significantly more prevalent than others while some tick species (H. kyasanursensis, H. turturis, H. spinigera, H. hystricis, H. aculeata, A. clypeolatum, D. auratus, and $N$. monstrosum) were relatively very rare. Moreover, all of these low prevalent tick species were observed in less than three hosts, probably indicating a restricted host range. Notably, for the first time in Sri Lanka, five tick species $(H$. turturis, H. aculeata, $H$ hyistricis, $H$. kyasanursensis, and D. auratus) which were previously recorded only in wildlife were recorded on livestock in the current study suggesting the possible interaction between wildlife and domestic animals and transmitting diseases from wildlife to livestock. Interestingly, though there was a low prevalent, these newly introduced tick species appear to have a wide geographical distribution and a host range.

It was clearly shown in the present study that livestock in Sri Lanka are considerably burdened with tick parasites and are at risk of contracting tick-borne diseases. For example, with the high abundance of $R$. boophilus on cattle and buffalo they are at a very high risk of contracting Theileria, Babesia, and Anaplasma parasites. Similarly, H. marginatum is abundant on buffalo and cattle and is a vector for Babesia. The tick species that are expanding their geographical distribution and host range (for example A. testudinarium and Dermacentor spp.) can be vectors for rickettsial diseases such asehrlichiosis, and anaplasmosis. Considering the tick species that are newly introduced to livestock from wildlife, Sri Lankan livestock as well as humans may beat an increased risk of contracting new diseases transmitted by these vectors. For example, H. spinigera and $H$. turturis, are vectors of Kyasanur forest disease and therefore there is a theoretical possibility that this disease may establish in Sri Lanka following introduction by migratory birds from South India (Acha and Szyfres 2003; Trapido et al., 1959; Verma et al., 1960; Seneviratna, 1965).

Ticks must be controlled if livestock production is to meet world needs for animal protein. Large numbers of ticksfeeding on livestock causes reduction of production and even could have leadsto loss of animals. In addition, tick bites also reduce the quality of hides. Apart from irritation and/or anemia in heavy infestations, ticks can cause severe dermatitis (FAO, 1998; L'Hostis and Seegers, 2002; Peter et al., 2005; Jongejan and Uilenberg, 2004; Stewart et al., 1981).Therefore, knowledge on the nature and habitats of the ticks and the diseasesthey transmit are vital in implementing effective control strategies. 


\section{ACKNOWLEDGEMENT}

Authors wish to thank Dr. Dimitry A. Apanaskevich of National Tick Collection, Georgia Southern University, USA for confirming the identity of certain tick specimens. D. Liyanaarachchi was supported by a GateMudaliar A.G. Thilakaratne research Fellowship (2008/2009) awarded by University of Peradeniya. Financial support to carry out this project was provided by National Research Council (Grant No 09-05). Authors also wish to thank all veterinarians and volunteers who helped in the collection of ticks and the members of Molecular Parasitology Laboratory in the Faculty of Veterinary Medicine and Animal Science, University of Peradeniya for helpful discussions.

\section{REFERENCES}

Acha, P. N. and Szyfres, B. (2003). Zoonoses and Communicable Diseases Common to Man and Animals ( $3^{\text {rd }}$ Ed.).Washington, D.C. Pan American Health Organization.

Bandaranayake, A (1961). A note on the occurrence of Babasia argentina in cattle in Ceylon. Ceylon Vet J.: ix:51-4.

Conrad, P.A., Kelly, B.G. and Brown, C.G.D. (1985). Intra erythrocytic schizogonyn of Theleriaannulata. Parasitol. 91, 67-82.

Crawford, M. (1935). Tick borne diseases of cattle in Ceylon. Tropical Agriculturist: 84:124.

Dilrukshi, P.R.M.P. (2002). Aspects of the ecology and morphotaxonomy of cattle ticks (Acar: Ixodidae) in Sri Lanka. Ph.D. Thesis, Post Graduate Institute of Science, University of Peradeniya, 424 pg.

FAO.(1998).Available at http://www.fao.org/ag/AGA/AGAH/PD/pages/tick01.htm), downloaded on 09-10-2012.

Frans, J. 2000. Final Report, Integrated Control of Ticks and Tick-Born Diseases(ICTTD). p. 4. (Available from: http://www.uu.nl/tropical.ticks) downloaded on 09-10-2012.

Geevarghese, G. and Mishra, A. (2011). Haemaphysalis ticks of India. $1^{\text {st }}$ edition.Elsevier USA.

Gehrke, F.S., Labruna, M.B., Camargo, L.M., Camargo,E.P., and Schumaker,T.T. (2002). Ticks of the state of Rondonia, Western Brazilian Amazon: detection of Borrelia sp.,Ehrlichia sp. and Rickettsia sp.by the use of polymerase chain reaction and southern blotting. In:XI International Congress of Acarology, 8-13 September 2002.Merida, Yucatan,Mexico.P.184-189.

Halim, S.R., Weilgama, D.J., Perera, P.S.G. and Fernando, S.T. (1983). Ixodidae ticks of goats in the dry zone of Sri Lanka. Sri Lanka Veterinary Journal, 31, 14-20.

Jongejan, F.and Uilenberg, G., (2004).The global importance of ticks. Parasitology.129, S3S14. 
Jorgensen, W.K., Weilgama, D.J., Navaratne, M., and Dalgliesh, R.J. (1992).Prevalence of Babasia bovis and Anaplasma marginale at selected localities in Sri Lanka. Trop.Animal Health Production.24, 9-14.

Kaiser, M.N. and Hoogstraal, H.(1964).The Haemaphysalis ticks (Ixodoidea,Ixodidae) of Pakistan, India and Ceylon, with keys to sub genera and species. Acaralogia.6,257-286.

Klompen, J.S.H, Black, W.C.I.V, Keirans, J.E, and Oliver J.H.J.R. (1996.)Evolution of ticks. Annual Rev Entomol.;41(1), 141-161.

Kocan, A.A., and Kocan, K.M. (1991).Tick transmitted protozoan diseases of wild life in North America. Bull. Soc. Vector Ecol. 16, 94-108.

Labruna, M.B. Whitworth, D.H. Bouyer, J.W.McBride,L.M.A. Camargo, E.P.Camargo, Popov V., andWalkerD.H(2004). Rickettsia bellii and Rickettsia amblyommii in Amblyomma ticks from the state of Rondonia.Western Amazon, Brazil.J.Med.Entomol.41, 1073-1081.

L'Hostis, M. and Seegers, H. (2002).Tick-borne parasitic diseases in cattle: Current knowledge and prospective risk analysis related to the ongoing evolution in French cattle farming systems. Vet.Res. 33(5), 599-611.

Lemos,E.R.S., Machado H.H. CouraJ.R., M.A.A.Guimaraea, S.R.Sanseverino, and Moura, A.(1997). Primary isolation of spotted fever group rickettsiae from Amblyommacooperi collected from Hydrochaerishydrochaeris in Brazil.Mem.Inst.Oswaldo Cruz 91, 273-275.

Nuttall, G.H.F. and Warburton, C. (1915) Ticks: A monograph of the Ixodidea. Part 111.The genus Haemaphysalis. Cambridge University Press.P.351- 550.

Perea, L.P., Peiris, J.S.M., and Weilgama.D.J. (1996). Nairobi sheep disease virus isolated from Haemaphysalisintermedia ticks collected in Sri Lanka. Annals of Tropical Medicine and Parasitology.90, 91-93.

Peter, R.J., van den Bossche, P., Penzhorn, B.L.and Sharp B. (2005).Tick, fly, and mosquito control - Lessons from the past, solutions for the future. Vet Parasitol. 132(3-4), 205-215.

Seneviratna, P. and Kumaraswamy S. (1960) The presence of Gonderia annulata in the ox in Ceylon. Ceylon Vet J: 8:26.

Seneviratna, P. and Dhanapala S.B. (1963). Ehrlichia bovis like organisms in cattle in Ceylon. Ceylon Vet J.xi:101.

Seneviratna, P. and Subasinghe D.H.A.(1963).The presence of Gonderia ovis (Rodhain, 1916) infection in goats in Ceylon. CeylonVet.J.xi (4), 21-23.

Seneviratna, P.(1965).The Ixodoidea (Ticks) of Ceylon. Parts ii and iii. Ceylon Vet J: xiii (2), 28-54.

Seneviratna, P. (1966). Ticks on Domestic Animals in Ceylon and diseases transmitted by them. Tropical Agriculturist. 122(1/2), 9-18. 
Sharif, M.(1928). A revision of the Indian Ixodidae, with special reference to the collection in the Indian Museum.Rec.Indian Mus.30,217-344.

Snelson J. T.(1975). Animal ectoparasites and disease vector causing major reduction in world food supplies.FAO Plant Protection Bulletin. 13, 103-114.

Sonenshine, D.E. (1991). Biology of ticks.Oxford University Press.Vol.1. New York, U.S.A.

Sonenshine, D.E.(1993). Biology of ticks.Vol.2.Oxford University Press.

Stewart, N.P., Dalgliesh, R.J. andTratt, T. (1981).Life-cycle of tick and tick fever parasites. Queensland Agriculture Journal. 107, 305-308.

Sturgess, G.W. (1917). Report of the Government Veterinary surgeon, Ceylon. Colombo: Government Printer: Part 4: FI.

Trapido H., Verma M.G.R., Rajagopalan P.K., and Rebello M.J. (1963). A guide to identification of all stages of the Haemaphysalis ticks of south India. Bulletin of entomological Research.Vol.55.Part 2.

Trapido, H., Rajagopalan, P.K., Work, T.H. and Varma, M.G.R. (1959).Kyasanur forest disease. Part viii. Isolation of Kyasanur forest disease virus from naturally infected ticks of the genus Haemaphysalis. Indian J.Med.Research47,133-138.

Weilgama D.J.(1985).Observations of Theileriosis among cattle and buffaloes in Sri Lanka. Proceedings of the thirty-ninth Annual General Meetings of the Sri Lanka Veterinary Association. S.L.Vet.J. 34, 64-75.

Weilgama D.J. (1999).Ectoparasites in "Water buffalo in Asia: iv diseases of the Buffalo" Published by SAREC/NASESA Buffalo Information and dissemination Programme, Sri Lanka.ISBN 955-590-026-4.pp.27.-35.

Weilgama.D.J.(2005).Ticks and tick borne diseases in Sri Lanka.In Asian Parasitology Series Monograph Vol.4.Eds.A. Yano, H. Nam,KhairulAnnuar A.J. Shen,A. Saito and I. Igarashi. The Federation of Asian Parasitologists.pp 243-256.

Varma, M.G.R., Webb,H.E. and K.M. Parri.(1960). Studies on the transmission of Kyasanur Forest Disease virus by Haemayphysalis spinigera Newman (sic). Tr. R. Soc. Trop. Med. Hyg. 54, 509-516. 